\title{
Effect of tungsten on the oxidation of alumina-forming austenitic stainless steel
}

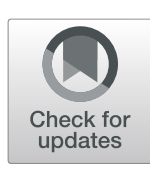

Jun-Yun Kang ${ }^{1^{*}} \mathbb{D}$, Heon-Young Ha' , Sung-Dae Kim, Jun Young Park', Min-Ho Jang ${ }^{1,2}$ and Tae-Ho Lee

\begin{abstract}
As more $\mathrm{W}$ replaced Mo in alumina-forming austenitic stainless steels, weight gain by oxidation decreased after $336 \mathrm{~h}$ at $1053 \mathrm{~K}$. Electron microscopy revealed slower growth of scale in the presence of more numerous second phases by $\mathrm{W}$ addition. The retardation of oxidation was attributed to the necessary partitioning of $\mathrm{W}$ in front of the metal-oxide interface. The $\mathrm{W}$-rich second phases interacted with growing oxides and finally transformed to fine particles of metallic $W$ alloy within the scale.
\end{abstract}

Keywords: Sainless steel, TEM, High temperature corrosion, Oxidation

\section{Introduction}

Many variants of austenitic stainless steels have been common materials in building various components which required long-term structural stability upon exposure to high temperature. The key properties for these applications are creep and oxidation-resistance. And enormous efforts have been devoted to their improvement in order to cope with the increasing service temperatures (Mayer and Masuyama 2008; Igarashi 2008).

The oxidation-resistance of conventional austenitic stainless steels is obtained by the formation of chromia $\left(\mathrm{Cr}_{2} \mathrm{O}_{3}\right)$ layer as the protective surface scale. On the other hand, a considerable number of attempts have been made to substitute it with alumina $\left(\mathrm{Al}_{2} \mathrm{O}_{3}\right)$ as a way to improve oxidation-resistance (Ramakrishnan et al. 1988; Yamamoto et al. 2007a; Yamamoto et al. 2007b; Brady et al. 2008). The latter has higher thermodynamic stability in oxygen, much slower growth rate and does not exhibit volatility in wet air (Yamamoto et al. 2007a; Yamamoto et al. 2007b; Brady et al. 2008; Opila 2004). Thus, the recent achievement in the development of alumina-forming austenitic stainless steels (AFA) (Yamamoto et al. 2007a; Yamamoto et al. 2007b; Brady et al. 2008) has attracted a number of subsequent investigates to assess their feasibility in various applications (Pint et al. 2013; Brady et al. 2013; He et al. 2014; Ejenstam and Szakálos 2015; Put

\footnotetext{
* Correspondence: firice@kims.re.kr

${ }^{1}$ Korea Institute of Materials Science, 797 Changwon-daero, Changwon,

Gyeongnam 51508, Republic of Korea

Full list of author information is available at the end of the article
}

et al. 2015) and to improve their properties (Brady et al. 2009; Yamamoto et al. 2009a; Brady et al. 2011a; Yamamoto et al. 2011; Yamamoto et al. 2013) as well as cost efficiency (Yamamoto et al. 2009b; Brady et al. 2014).

Alloying with Mo and W have been frequently used to enhance the performance of various steels for hightemperature applications (Mayer and Masuyama 2008; Igarashi 2008; Liu and Fujita 1988; Tsuchida et al. 1995; Miyata and Sawaragi 2001; Cui et al. 2011; Jang et al. 2015; Hosoi et al. 1996; Yun et al. 2011; Yun et al. 2012), while their effects on creep-resistance have been more focused (Igarashi 2008; Liu and Fujita 1988; Tsuchida et al. 1995; Miyata and Sawaragi 2001; Cui et al. 2011; Jang et al. 2015). They are transition metals belonging to the same group VI in periodic table, have approximately identical atomic radius ( 2.17 and $2.18 \AA$ respectively) (Periodic table from the Royal Society of Chemistry n.d.), thus are usually regarded to play parallel roles in Fe-base alloys. Based on this perception, the following Mo equivalent which was the normalized weight fraction by approximate ratio of their atomic mass has been widely used by steel metallurgists (Liu and Fujita 1988; Tsuchida et al. 1995; Miyata and Sawaragi 2001; Cui et al. 2011; Jang et al. 2015).

$$
\mathrm{Mo}_{\mathrm{eq}}=[\mathrm{wt} . \% \text { of Mo }]+0.5[\mathrm{wt} . \% \mathrm{of} \mathrm{W}]
$$

With regard to the comparison of Mo and W effect, several works indicated superior effectiveness of $\mathrm{W}$ on creepresistance (Igarashi 2008; Liu and Fujita 1988; Tsuchida et al. 1995; Miyata and Sawaragi 2001; Cui et al. 2011; Jang 
et al. 2015). In fixed $\mathrm{Mo}_{\text {eq }}$, increased $\mathrm{W}$ (consequently decreased Mo) generally increases creep rupture strength or time to rupture via modification of precipitates (Igarashi 2008; Tsuchida et al. 1995; Miyata and Sawaragi 2001; Cui et al. 2011; Jang et al. 2015). On the other hand, a more limited number of works (Hosoi et al. 1996; Yun et al. 2011; Yun et al. 2012) were found about their effect on oxidation-resistance. Although both elements were positively effective up to certain amounts of addition (Hosoi et al. 1996; Yun et al. 2011; Yun et al. 2012), the comparison of their effectiveness was not presented.

In this work, oxidation behaviors of AFAs with varying Mo and W contents were analyzed and superior effectiveness of $\mathrm{W}$ on oxidation-resistance was observed. Therefore, detailed microscopic works on the characteristic features of oxide layers and interfaces are presented to address the effect of $\mathrm{W}$ in comparison with Mo, which should contribute to further optimization and evolution of AFAs.

\section{Material and methods}

One of the original AFAs from (Yamamoto et al. 2007a) and its variants with varying Mo and $\mathrm{W}$ contents were prepared. The target and the measured compositions are listed in Table 1. Following the target composition, $\mathrm{Mo}_{\mathrm{eq}}$ was controlled to be close to 2.5. The designations of the alloys, i.e. W0-W5 describe their W contents which substituted for equivalent Mo contents.

Cast ingots by vacuum induction melting were reheated to $1523 \mathrm{~K}$, held for $2 \mathrm{~h}$, hot rolled between 1373 and $1173 \mathrm{~K}$ by thickness reduction of $50 \%$ and quenched in water. Then, the hot rolled plates were cold rolled by thickness reduction of $60 \%$, annealed at $1523 \mathrm{~K}$ for an hour and quenched. Finely polished surfaces of the annealed specimens were exposed to hot atmosphere kept at $1053 \mathrm{~K}$ for up to $336 \mathrm{~h}$. And weight gains by oxidation were measured.

The microstructures around surface scales were analyzed on two representative specimens, i.e. W0 and W5 which had the minimum and the maximum $\mathrm{W}$ contents respectively. A field emission scanning electron microscope (SEM, JSM-7001F by JEOL) and a field emission transmission electron microscope (TEM, JEM-2100F by JEOL) were used. Electron-transparent specimens for TEM were fabricated by a focused ion beam system (FIB, JIB-4601F by JEOL).

\section{Results}

Weight gains according to the alloy compositions after $336 \mathrm{~h}$ of oxidation are presented in Fig. 1. As W content increased, i.e. substituted for more equivalent content of Mo, weight gains continued to decrease. Thus, at least for the given conditions and durations of oxidation, it could be said that W enhanced oxidation-resistance more effectively than Mo.

The initial microstructures prior to oxidation exhibited negligible differences according to the alloy compositions, which is well represented in Fig. 2. It presents the initial microstructures of W0 and W5, both of which exhibited typical microstructures of AFAs (Pint et al. 2013; Yamamoto et al. 2011; Jang et al. 2015) by annealing and homogenization at high temperatures $(1523 \mathrm{~K}$ in the present work). They had austenitic matrix of comparable grain sizes (approximately $100 \mu \mathrm{m}$ in average) with undissolved primary $\mathrm{Nb}(\mathrm{C}, \mathrm{N})$ particles (the bright spots in Fig. 2) of similar distribution.

Figure 3 presents a scanning transmission electron image in dark field mode (STEI-DF) and elemental distribution maps by energy dispersive spectroscopy (EDS) around the scale of W5 after a short duration (30 min) of oxidation. They represent the general constitution of the oxide scale. It could be known that the scale consisted of multiple layers of different compositions, which led to the varying brightness of the scale in the micrographs by compositional contrast. The outermost layer was (Fe, $\mathrm{Mn}, \mathrm{Cr}$ )-rich oxide beneath which more $\mathrm{Cr}$ enriched layer existed. The darker inner layer adjacent to the metallic (austenitic) substrate was Al-rich oxide, i.e. alumina. This multi-layered structure of scale well accords with some previous observations on the scale of AFAs (He et al. 2014; Brady et al. 2011a; Kang et al. 2015; Brady et al. 2011b; Rother et al. 2012). Beneath the scale of W5, there was a characteristic region in which dark and bright volumes alternated. And the W map in

Table 1 Chemical compositions of the alloys (in wt.\%)

\begin{tabular}{|c|c|c|c|c|c|c|c|c|c|c|c|}
\hline Alloy & $C$ & $\mathrm{Si}$ & $\mathrm{Mn}$ & $\mathrm{Al}$ & $\mathrm{Cr}$ & $\mathrm{Ni}$ & Mo & W & $\mathrm{Mo}_{\mathrm{eq}}$ & $\mathrm{Nb}$ & \\
\hline Target & 0.08 & 0.15 & 2.00 & 2.50 & 14.00 & 20.00 & \multicolumn{3}{|c|}{$\mathrm{Mo}_{\mathrm{eq}}=2.50$} & 0.85 & \multirow{7}{*}{$\begin{array}{l}\text { B: } 0.01 \\
\text { P: } 0.01 \\
\text { Fe: Bal. }\end{array}$} \\
\hline Wo & 0.08 & 0.16 & 2.02 & 2.45 & 14.28 & 20.74 & 2.46 & 0.01 & 2.47 & 0.82 & \\
\hline W1 & 0.08 & 0.16 & 1.99 & 2.45 & 14.25 & 20.48 & 2.06 & 0.89 & 2.50 & 0.81 & \\
\hline W2 & 0.08 & 0.15 & 1.95 & 2.53 & 14.15 & 20.21 & 1.69 & 1.77 & 2.57 & 0.85 & \\
\hline W3 & 0.08 & 0.15 & 1.94 & 2.60 & 14.07 & 19.95 & 1.02 & 3.07 & 2.56 & 0.86 & \\
\hline W4 & 0.08 & 0.15 & 1.92 & 2.57 & 14.03 & 19.84 & 0.88 & 3.65 & 2.71 & 0.85 & \\
\hline W5 & 0.08 & 0.15 & 1.93 & 2.57 & 14.01 & 19.66 & 0.41 & 4.63 & 2.73 & 0.82 & \\
\hline
\end{tabular}




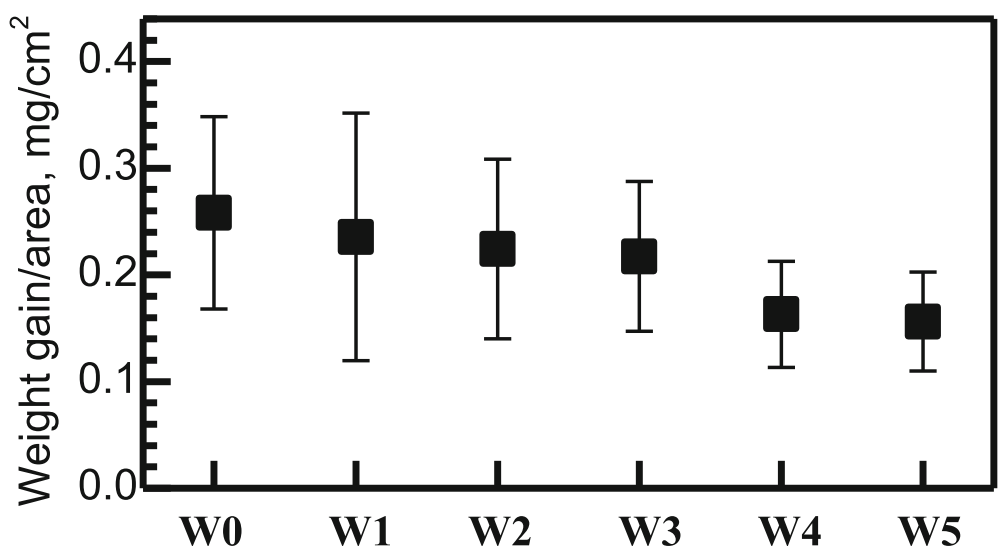

\section{Alloy}

Fig. 1 Weight gain of the alloys after $336 \mathrm{~h}$ of oxidation at $1053 \mathrm{~K}$ (error bars represent standard deviations)

Fig. 3 shows that the bright volume is rich in $\mathrm{W}$ and indicates the existence of W-rich second phases. In Table 2, the average compositions of the two characteristic features (dark and bright) are presented with those of the alumina layer and the metallic matrix $(100 \mu \mathrm{m}$ below the interface between the substrate and the scale). All of them were measured by EDS, thus it should be noted that a considerable deviation from the actual composition was inevitable due to limited spatial resolution. Albeit this, it was apparent that the dark volume was much richer in $\mathrm{O}$ and $\mathrm{Al}$ and more deficient in $\mathrm{Cr}$ than the matrix. On the other hand, the dark volume exhibited much lower $\mathrm{O}$ and $\mathrm{Al}$ content than the alumina layer whilst $\mathrm{Fe}$ and $\mathrm{Ni}$ contents were close to those of the matrix.

Figures 4 and 5 represent the microstructures around the scale of W0 and W5 after $30 \mathrm{~min}$ and $336 \mathrm{~h}$ of oxidation respectively. In Fig. 4b, a part of Fig. 3 is included. And in Fig. 5, backscattered electron images from the SEM (SEM-BEI) are presented instead of STEIDFs in the consideration of substantial scale growth, while they are similar in the characteristics of image contrast with STEI-DFs. As can be deduced from Fig. 1, the increased $\mathrm{W}$ content retarded the growth of scales from the very early stages of the oxidation test. As shown in Fig. 4, alumina layer (the continuous darkest layer) was evidently thinner in W5 after 30 min of oxidation. And overall thickness of scale was thinner in W5 after $336 \mathrm{~h}$, as presented in Fig. 5. It should be also noted that there were much more bright second phases in W5 from the early stage. They were absent in W0 after 30 min and only a few were found along the interface between the metallic substrate and the oxide scale as shown in Figs. 4a and 5a respectively. By contrast, a


Fig. 2 Initial microstructures prior to oxidation: a W0, b W5 


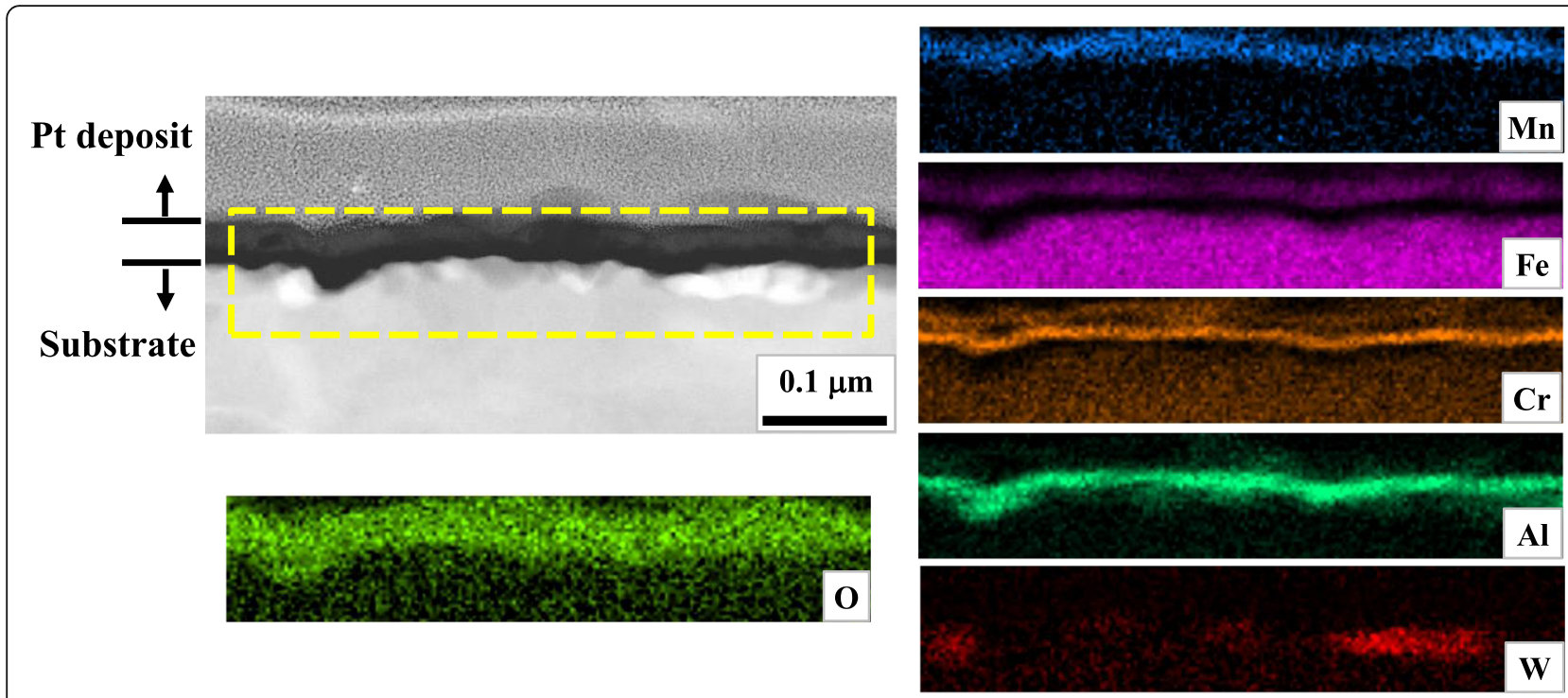

Fig. 3 Microstructure around the scale of W5 after 30 min of oxidation (STEI-DF and elemental maps by EDS within the broken box)

considerable number of them were found along the metal-oxide interface in W5 after $30 \mathrm{~min}$, although they were hardly found in the matrix as shown in Fig. 4b. After prolonged duration, the matrix of W5 was also populated with them as shown in Fig. 5b.

Figure 6 provides more detailed information on the microstructure around the scale of W5 after $336 \mathrm{~h}$. The local chemistry by EDS and the symmetry and spacing of the spots in selected area diffraction patterns (SADP) by nano-beam diffraction method presented the identification of the oxides and the second phases. The innermost Al-rich layer was definitely identified as alumina $\left(\alpha-\mathrm{Al}_{2} \mathrm{O}_{3}\right)$ while a coarse bright second phase beneath the metal-oxide interface was identified as Laves-phase. Between the outermost layer which was known as $(\mathrm{Fe}$, Cr, Mn)-rich spinel (Brady et al. 2011a; Kang et al. 2015) and the innermost alumina layer, there was an intermediate layer in which many bright granules were embedded in the dark alumina layer. Most of the granules were richer in $\mathrm{Cr}$ than the surrounding alumina. Some distinctly brighter particles were frequently found inside the scale of W5 as represented within the broken box in the micrograph of Fig. 6. The identification of them would be the most interesting finding in Fig. 6. The brightest second phase was rich in $\mathrm{W}$ as shown in the

Table 2 Average compositions of the characteristic features in Fig. 3 measured by EDS (at. \%)

\begin{tabular}{lllllllllll}
\hline Feature & $\mathrm{O}$ & $\mathrm{Al}$ & $\mathrm{Si}$ & $\mathrm{Cr}$ & $\mathrm{Mn}$ & $\mathrm{Fe}$ & $\mathrm{Ni}$ & $\mathrm{Nb}$ & $\mathrm{Mo}$ & $\mathrm{W}$ \\
\hline Alumina & 48.62 & 41.88 & 1.16 & 1.03 & 0.00 & 4.26 & 2.00 & 0.66 & 0.18 & 0.21 \\
Matrix & 0.91 & 3.09 & 0.00 & 15.55 & 0.80 & 58.05 & 18.94 & 0.84 & 0.41 & 1.41 \\
Dark & 17.41 & 11.89 & 0.73 & 6.98 & 0.00 & 43.79 & 16.20 & 0.44 & 0.81 & 1.76 \\
Bright & 4.99 & 1.43 & 1.40 & 8.87 & 0.00 & 55.74 & 17.61 & 0.17 & 1.92 & 7.87 \\
\hline
\end{tabular}

W map. In addition, the average composition of these types of particles by EDS is also presented in Table 3. Although it exhibited high $\mathrm{O}$ and $\mathrm{Al}$ contents due to surrounding alumina layer, the ratio of $\mathrm{W}$ to other metallic contents were distinctly higher than in the other bright W-rich second phases beneath the metal-oxide interface. Its SADP showed the typical symmetry of body centered cubic (bcc) lattice with lattice parameter of about $3 \AA$, which very well accords with metallic Wbased alloys of bcc lattices (Grum-Grzhimailo and Prokof'ev 1961; Taylor and Doyle 1965).

\section{Discussion}

From approximately the same initial microstructures which are represented in Fig. 2, the effect of initial microstructure could be disregarded in the following discussion on the influence of W. On the other hand, as shown in Figs. 4 and 5, the evolution of microstructure during oxidation at the given temperature (1053 $\mathrm{K})$ varied with the amount of $\mathrm{W}$ which substitutes for Mo. Besides the decreasing thickness of scale, the most noticeable change by $\mathrm{W}$ alloying was the increased second phase both at the metal-oxide interface and within the matrix.

Figure 7 presents some calculations of thermodynamic equilibria in matrix at $1053 \mathrm{~K}$. The target compositions in Table 1 with increasing W (i.e. decreasing Mo) contents were submitted to Thermo-Calc 3.0 software (Anderson et al. 2002) with TCFE7 database (Thermo-Calc Software TCFE7 Steels/Fe-alloys database version 7 n.d.). Figure $7 \mathrm{a}$ is the predicted volume fractions of equilibrium phases with $\mathrm{W}$ content, which shows the increasing Laves-phase with increasing $\mathrm{W}$ while the other second phase, i.e. $\mathrm{NbC}$ is hardly affected. In Fig. $7 \mathrm{~b}$, the 


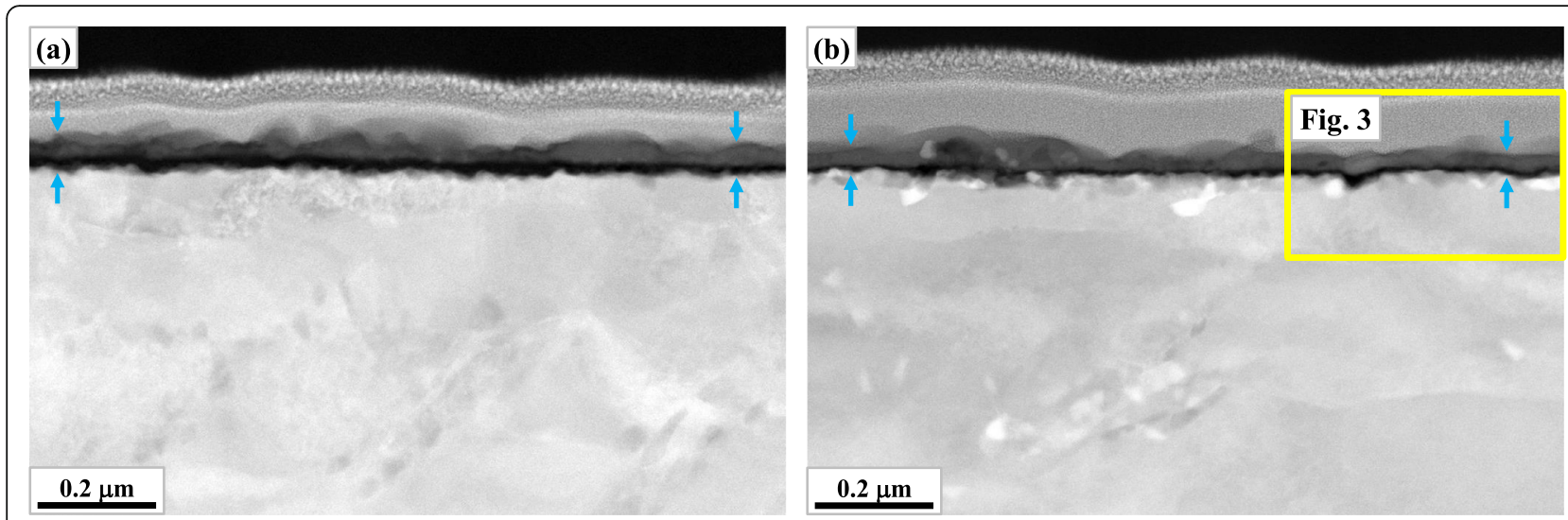

Fig. 4 Microstructures around the scales after 30 min of oxidation (STEI-DF): a WO, b W5 (the scale region is indicated by the arrows and the area within the solid box corresponds to a part of Fig. 3)

equilibrium concentration of $\mathrm{W}$ in the increasing Lavesphase also increases with nominal W content. Ideally, the constitution of Laves phase should transform from $\mathrm{Fe}_{2} \mathrm{Mo}$ to $\mathrm{Fe}_{2} \mathrm{~W}$ following Fig. 7b. Although both Mo and $\mathrm{W}$ were known as Laves-phase former (Igarashi 2008; Jang et al. 2015; Horita et al. 2008; Pavlů and Šob 2012; Lu et al. 2014), it could be known that W was more effective in the stabilization of Laves-phase when incorporated into it (Igarashi 2008; Jang et al. 2015; Lu et al. 2014). In Fig. 6, a W-rich Laves phase was identified below the metal-oxide interface of W5, which supported the thermodynamic predictions in Fig. 7.

Phase equilibria under oxidation could be also predicted with addition of database for various oxides. Phase fractions of W0 and W5 with oxygen partial pressure $\left(\mathrm{pO}_{2}\right)$ were obtained by appending SSUB4 (Thermo-Calc Software SSUB4 Substances database version 4 n.d.) database to the above one (TCFE7). In the calculation, the measured compositions in Table 1 were used and the results under substantially low $\mathrm{pO}_{2}\left(10^{-30}\right.$ $-10^{-26} \mathrm{~atm}$, it should be noted that the equilibrium
$\mathrm{pO}_{2}$ for alumina at $1273 \mathrm{~K}$ was only about $10^{-37}$ atm for example (Khanna 2002).) are presented in Fig. 8 to approximate the reactions near substrate. In both alloys, alumina is preferred at low $\mathrm{pO}_{2}$ and other $\mathrm{Cr}, \mathrm{Mn}$ or $\mathrm{Si}$ containing oxides increases with increasing $\mathrm{pO}_{2}$, which exhibits good coherence with the observed compositional and structural gradient along the thickness of the scale in Fig. 3 (although not presented for convenience, $\mathrm{Cr}_{2} \mathrm{FeO}_{4}$ spinel which can represent the observed outermost $\left(\mathrm{Fe}, \mathrm{Cr}\right.$ )-rich oxide is stabilized with $\mathrm{pO}_{2}$ over $10^{-23}$ ). W0 and W5 exhibit very small difference in the constitution of oxides, whereas Laves-phase in W5 exhibits substantial stability against oxidation. Additionally, it is predicted to transform into $\mu$-phase $\left(\mathrm{Fe}_{7} \mathrm{~W}_{6}\right)$ of higher $\mathrm{W}$ content with increasing $\mathrm{pO}_{2}$ due to the equilibrium with the matrix and other oxides, however not to transform into any W-based oxides within the present range of calculations.

The predicted stability of the second phases, whether they are Laves, $\mu$-phase or others, can reflect the more numerous bright $\mathrm{W}$-rich second phases concentrated at
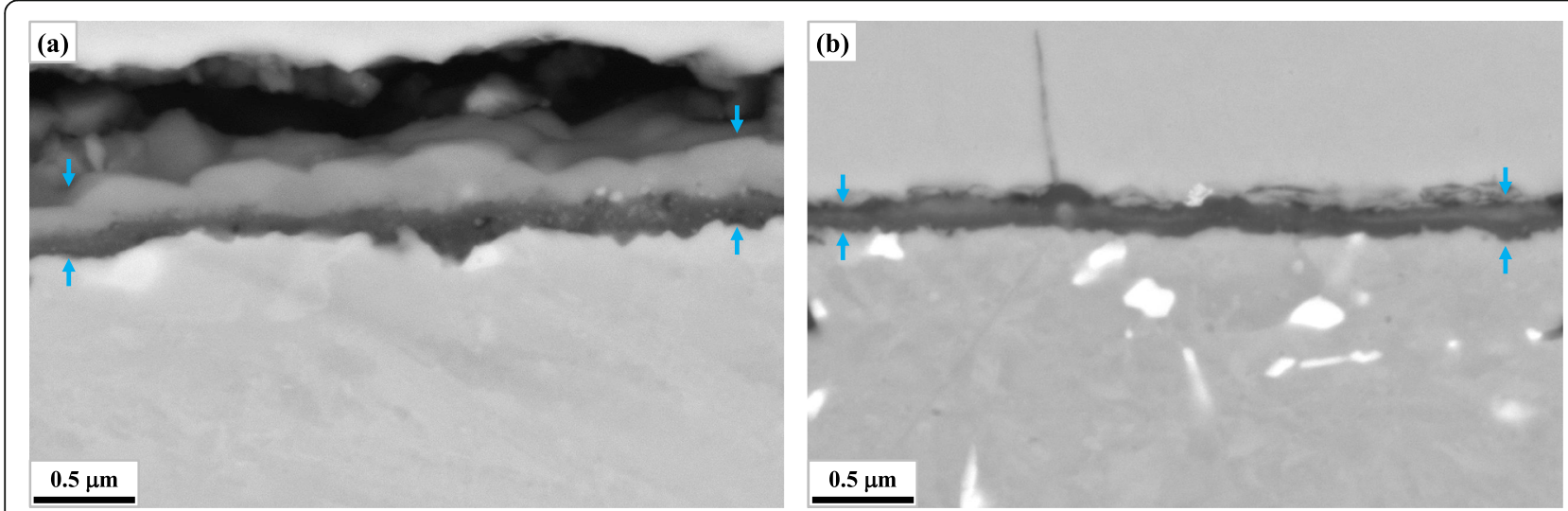

Fig. 5 Microstructures around the scales after $336 \mathrm{~h}$ of oxidation (SEM-BEI): a W0, b W5 


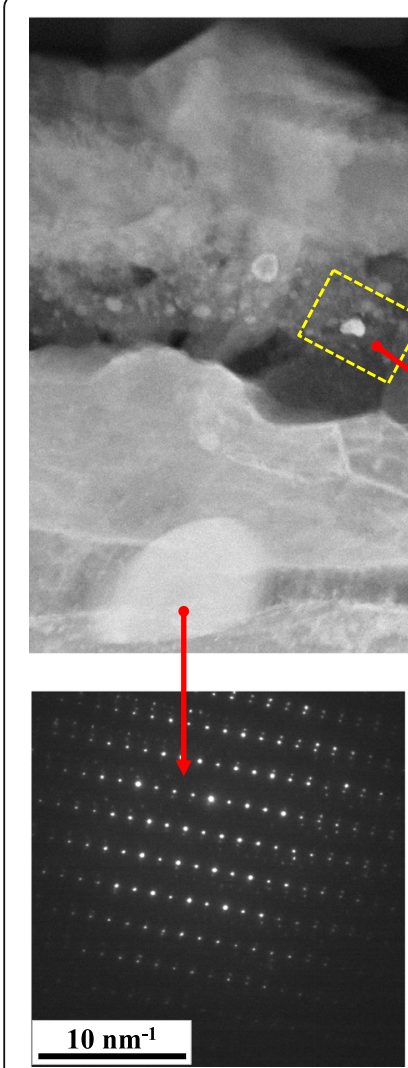

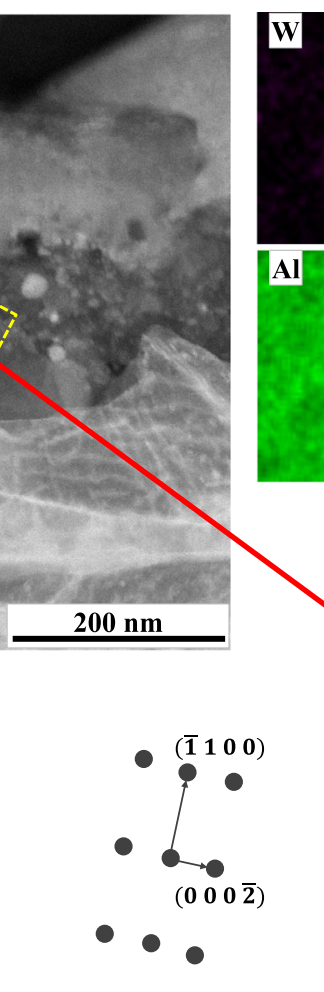



Al
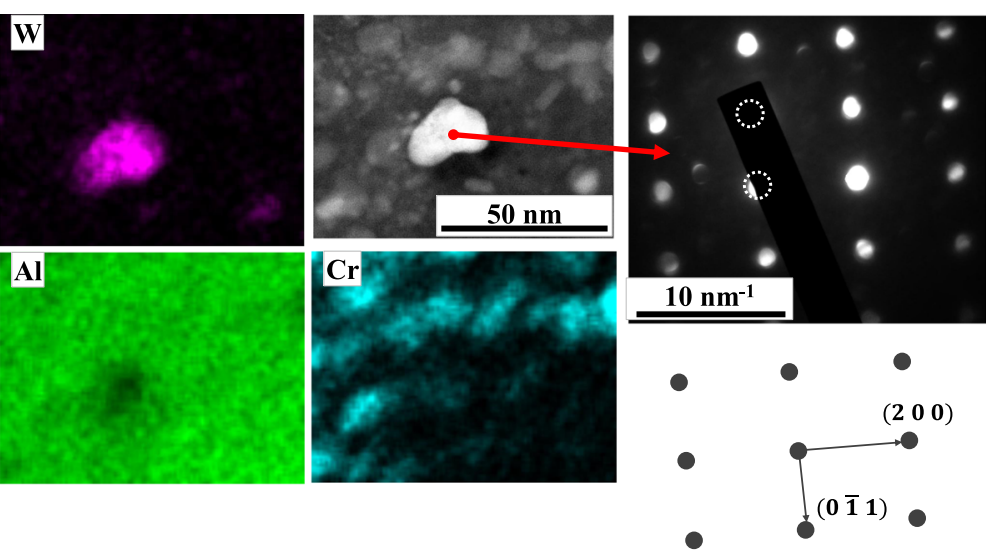

Z // [011]: bcc-W

Fig. 6 Analyses on the oxides and the second phases near the metal-oxide interface of W5 after $336 \mathrm{~h}$ of oxidation

the interface of W5 from the early stage of oxidation as shown in Fig. 4b. And this could affect the advance of oxide toward the substrate, i.e. lead to slower oxidation kinetics as presented in Fig. 1. It could be also closely correlated to the formation of the characteristic particle of metallic W alloy within the scale in Fig. 6.

Fig. 9 schematically depicts the progress of oxidation in W5 which can be expected from the above discussions on thermodynamic equilibrium. In Fig. 9a, upon exposure to hot atmosphere, it would form ( $\mathrm{Fe}, \mathrm{Cr}$, $\mathrm{Mn}$ )-rich oxides due to initially high $\mathrm{pO}_{2}$ at the bare metallic surface. And beneath this primary oxide layer, other metallic elements such as $\mathrm{Al}$, Mo and W which have limited contribution to the formation of the primary scale would be enriched. Due to the protection by the primary scale, $\mathrm{pO}_{2}$ at this region should be much lower and alumina layer which is thermodynamically favored in lower $\mathrm{pO}_{2}$ should form as depicted in Fig. 9b. The intermediate $\mathrm{Cr}$-richer layer of oxide between the

Table 3 Average composition of the bright W-rich particles inside the scale of W5 by EDS (at. \%)

\begin{tabular}{llllllllll}
\hline $\mathrm{O}$ & $\mathrm{Al}$ & $\mathrm{Si}$ & $\mathrm{Cr}$ & $\mathrm{Mn}$ & $\mathrm{Fe}$ & $\mathrm{Ni}$ & $\mathrm{Nb}$ & $\mathrm{Mo}$ & $\mathrm{W}$ \\
\hline 48.84 & 24.78 & 0.00 & 3.18 & 0.39 & 2.63 & 0.32 & 1.19 & 2.83 & 15.84 \\
\hline
\end{tabular}

two layers which was observed in Fig. 3 is omitted for brevity. Beneath the alumina layer, $\mathrm{pO}_{2}$ must be further lowered and the growth of scale is decelerated. Mo and W should be still enriched beneath the metal-oxide interface if the prior oxides should reject them due to insufficient miscibility. The process depicted in Fig. 9a-b should be common for all the alloys (W0-W5) and can be speculated from the phase equilibria in Fig. 8, although they only consider global equilibrium but not the local compositional variations of substrate (i.e. enrichment of some elements beneath the interface) in the progress of oxidation.

Figure 9c illustrates the oxidation stage corresponding to Figs. 3 and 4b. As shown by the alternating dark and bright volumes in the shallow region just beneath the interface, phase separation by precipitation of the bright $\mathrm{W}$ (and also Mo)-rich second phases takes place, which precedes that in the substrate because of the condensed Mo and W beneath the interface. Figure $9 \mathrm{c}-1$ is the magnification of the region within the broken box in Fig. 9c and illustrates the elemental partitioning which is required for the phase separation. Mo and W should enter the second phases with their growth while other elements such as $\mathrm{Al}$ should be rejected from them. Thus the neighboring volumes should become rich in $\mathrm{Al}$ as 

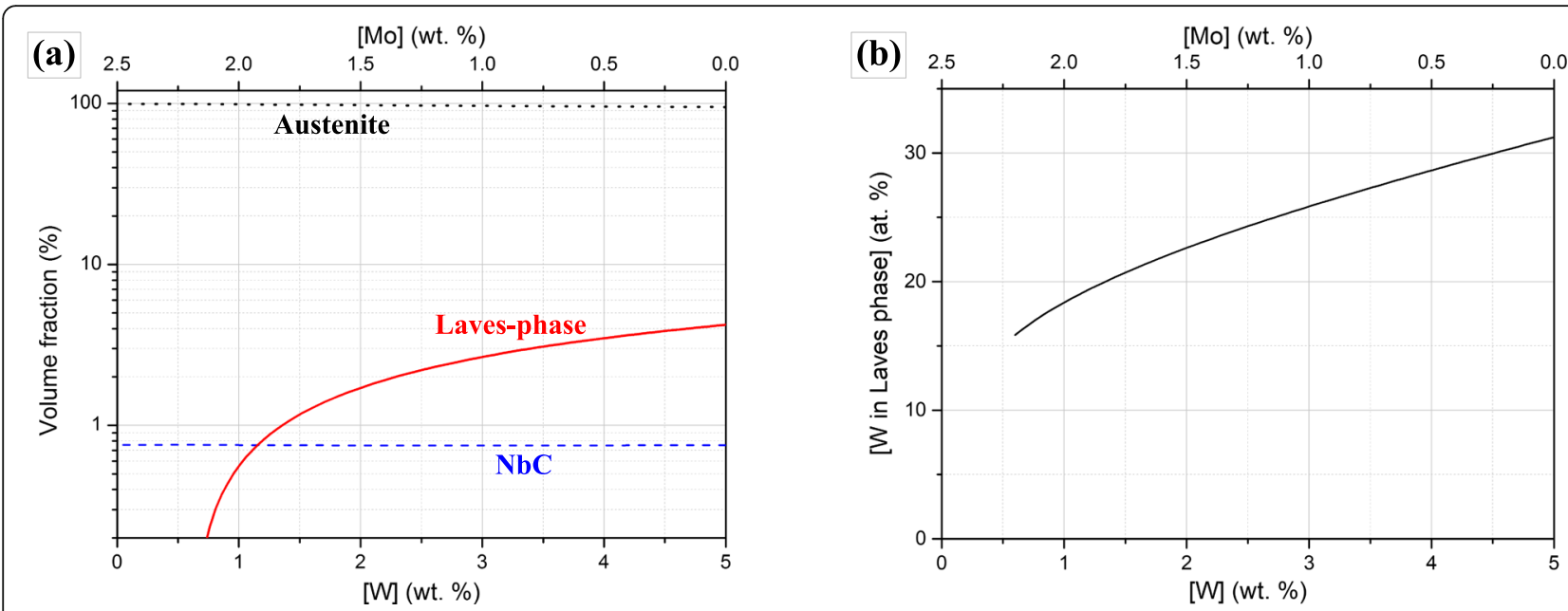

Fig. 7 Thermodynamic equilibria in the substrate with the target composition $\left(\mathrm{Mo}_{\mathrm{eq}}=2.5\right)$ at $1053 \mathrm{~K}$ according to nominal W content: a phase equilibria, b equilibrium W content in Laves phase (note that the calculation with instable Laves-phase is indicated)

confirmed in Table 2, which may partly contribute to their darkness in the STEI-DFs by compositional contrast. And they are also richer in $\mathrm{O}$ which infiltrated through the scale. These characteristic volumes should be transient structures which progressively transform to alumina with more $\mathrm{O}$ absorbed and could be temporarily termed as pro-alumina in this study. They were also found in W0 as shown in Fig. 4a, however the characteristic phase separation did not appear due to the less effectiveness of Mo in the formation of second phases as represented in Fig. 7a.

The existence and the characteristic compositions of pro-alumina could present some significant clues to the mechanisms of oxidation in AFAs. For instance, it can be known that the growth of alumina is governed by the reactions at the metal-oxide interface which should be controlled by the arrival of $\mathrm{O}$ passing through the priorly formed scale and by the elemental partitioning for the phase separation. In Table 2, the alumina layer exhibited very low levels of Mo and W, which implies that they should be rejected from pro-aluminas for their transform to alumina. An increasing fraction of $\mathrm{W}$ which is slower diffusant than Mo (Alberry and Haworth 1974) must retard the kinetics of this partitioning process at the interface and subsequently of the oxidation.

The fine metallic W alloy embedded in the scale (Fig. 6) indicates the instability of the W-rich second phases with increasing $\mathrm{pO}_{2}$ and the relative inertness of $\mathrm{W}$ against $\mathrm{O}$ in the given alloy system. The predicted phase equilibrium in Fig. 8b indeed shows the instability of Laves phase at increased $\mathrm{pO}_{2}$ and possible transformation into another phase, i.e. $\mu$-phase. Additionally, at least in the given range of $\mathrm{pO}_{2}$ in Fig. 8, there was no W-based oxide predicted. Although it can fail in the
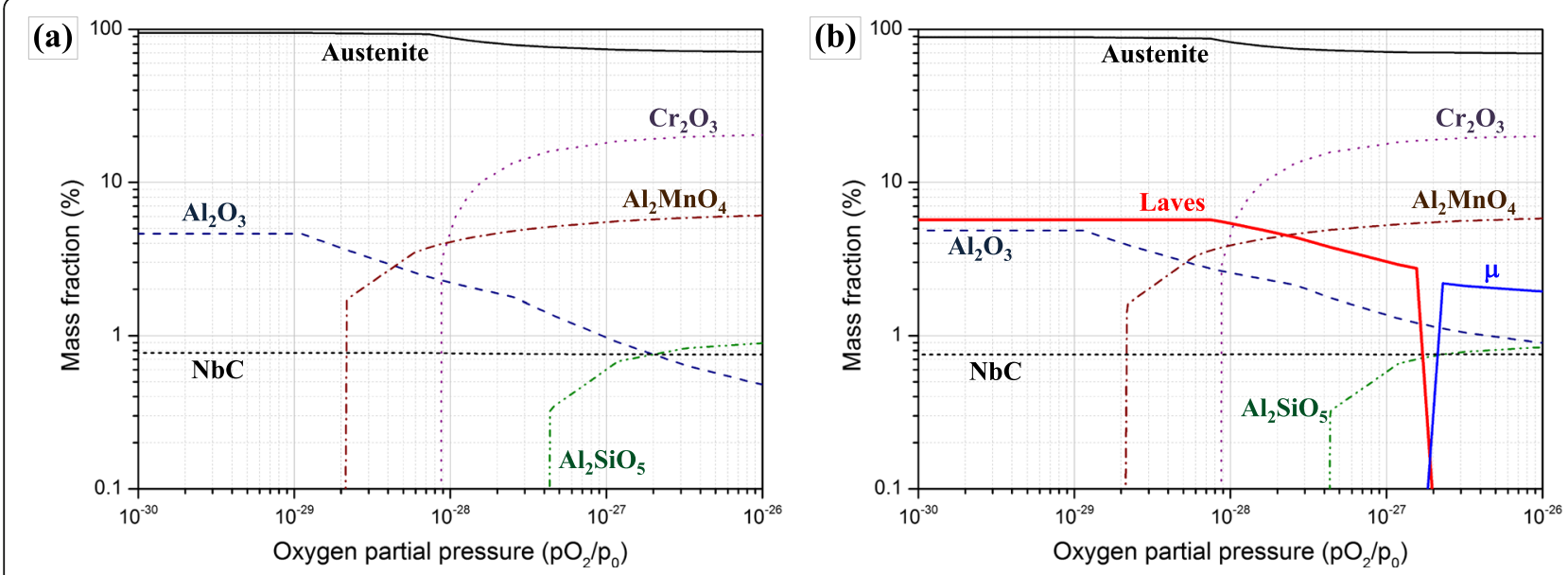

Fig. 8 Phase equilibria at $1053 \mathrm{~K}$ according to oxygen partial pressure: a W0, b W5 




exact identification of the initial and the final form of the W-rich second phase owing to various local and dynamic variability in the surface reaction as well as to incomplete databases, Fig. $8 \mathrm{~b}$ is partly successful in the prediction of their transformation behavior with increased $\mathrm{pO}_{2}$. Through the transformation, an initial W-rich second phase would transform into a phase richer in $\mathrm{W}$ by rejection of $\mathrm{Fe}$ and other minor oxide-forming elements which react the surrounding oxygen, as indicated in Fig. 9c-1. With the growth of scale, the metal-oxide interface sweeps across the initial array of the second phases. Those second phases could be placed under increased $\mathrm{pO}_{2}$ as the more protective alumina layer passes by and the less protective oxide layers surrounds them. The continued rejection of $\mathrm{Fe}$ and other oxide-formers to feed the surrounding oxides can finally leave the fine precipitates of the metallic W alloy in Fig. 6, which is also depicted in Fig. 9d. Because of the phase equilibria predicted in Fig. 7a, the substrate region which was considerably apart from the initial metal-oxide interface should precipitate Laves-phases as confirmed in
Fig. 6. And some of them would make contact with the advancing metal-oxide interface and also begin to interact with the growing oxides as depicted in Fig. $9 \mathrm{~d}$ because of their incomplete stability under increased $\mathrm{pO}_{2}$.

\section{Conclusions}

In this work, the effects of W on the oxidation of AFA were investigated with the alloys W0-W5 in which varying fractions of Mo were substituted with equivalent amounts of W. Weight gain after $336 \mathrm{~h}$ of exposure to hot atmosphere at $1053 \mathrm{~K}$ decreased as $\mathrm{W}$ content increased. From the microscopic observations on W0 and W5 which had the smallest and the largest amount of W respectively, the superior effectiveness of $\mathrm{W}$ on the retardation of scale growth was confirmed.

Increasing amount of $\mathrm{W}$ stabilized Laves-phase in matrix following the phase equilibria. W in the metallic substrate was condensed near the metal-oxide interface due to the loss of other elements by oxidation, which led to the profuse precipitation of $\mathrm{W}$-rich second phases preferentially at the interface. By the pro-alumina which 
would transform to alumina and the W-rich second phases, the characteristic local feature, i.e. the alternating brightness beneath the interface was observed in the micrographs. Additionally, from the compositional variations by the phases near the interface, it could be interpreted that the required partitioning of $\mathrm{W}$ between the phases contributed to the slower advance of the interface. Thus, the initial fine dispersion of the W-rich second phases could act as obstacles against the interface.

In prolonged oxidation, fine particles of metallic $\mathrm{W}$ alloy were found within the scale of W5. They could be supposed to transform from the initial W-rich second phases at the metal-oxide interface with increasing oxygen partial pressure, which tells the instability of the Wrich second phases within the growing oxides.

\section{Acknowledgements}

This work was funded by the Fundamental R\&D Program of Korea Institute of Materials Science (KIMS), PNK5220 and PNK6220.

\section{Authors' contributions}

J-YK designed the experiments, performed a part of TEM works, thermodynamic calculations and prepared the manuscript. $\mathrm{H}-\mathrm{YH}$ provided the results of the high-temperature oxidation tests. S-DK prepared the specimens using FIB and performed a part of TEM works. J-YP operated FIB for specimen preparation and fabricated the ingots of alloys. M-HJ carried out many metallographic tasks for SEM works. T-HL designed the experiments and interpreted the diffraction patterns. All authors read and approved the final manuscript

\section{Funding}

This work was funded by the Fundamental R\&D Program of Korea Institute of Materials Science (KIMS), PNK5220 and PNK6220.

\section{Availability of data and materials}

The data and the materials in the current manuscript cannot be shared because they also constitute a few on-going works, and the authors do not have the right to open them.

\section{Competing interests}

The authors declare that they have no competing interests.

\section{Author details}

${ }^{1}$ Korea Institute of Materials Science, 797 Changwon-daero, Changwon, Gyeongnam 51508, Republic of Korea. ${ }^{2}$ Present Address: Hyundai Steel, 1480, Bukbusaneop-ro, Dangjin-Si, Chungnam 31719, Republic of Korea.

Received: 29 August 2019 Accepted: 21 October 2019

Published online: 14 November 2019

\section{References}

P.J. Alberry, C.W. Haworth, Interdiffusion of $\mathrm{Cr}$, Mo, and W in iron. Met. Sci. 8, 407-412 (1974)

J.O. Anderson, T. Helander, L. Höglund, P.F. Shi, B. Sundman, Thermo-Calc \& DICTRA, computational tools for materials science. Calphad 26, 273-312 (2002)

M.P. Brady, M. Fayek, J.R. Keiser, H.M. Meyer III, K.L. More, L.M. Anovitz, D.J. Wesolowski, Wet oxidation of stainless steels: New insights into hydrogen ingress. Corros. Sci. 53, 1633-1638 (2011b)

M.P. Brady, J. Magee, Y. Yamamoto, D. Helmick, L. Wang, Co-optimization of wrought alumina-forming austenitic stainless steel composition ranges for high-temperature creep and oxidation/corrosion resistance. Mater. Sci. Eng. A590, 101-115 (2014)

M.P. Brady, K.A. Unocic, M.J. Lance, M.L. Santella, Y. Yamamoto, L.R. Walker, Increasing the upper temeprature oxidation limit of alumina forming austenitic stainless steels in air with water vapor. Oxid. Met. 75, 337-357 (2011a)

M.P. Brady, Y. Yamamoto, G. Muralidharan, H. Rogers, B.A. Pint, Deployment of alumina forming austenitic stainless steel, DOE report: ORNL/TM-2013/479 (2013)

M.P. Brady, Y. Yamamoto, M.L. Santella, P.J. Maziasz, B.A. Pint, C.T. Liu, H. Bei, The development of alumina-forming austenitic stainless steels for hightemperature structure use. JOM 60, 12-18 (2008)

M.P. Brady, Y. Yamamoto, M.L. Santella, L.R. Walker, Composition, microstructure, and water vapor effects on internal/external oxidation of alumina-forming austenitic stainless steels. Oxid. Met. 72, 311-333 (2009)

H. Cui, F. Sun, K. Chen, J. Wu, Combined effect of co and W on deformation resistance of $12 \mathrm{Cr}$ heat-resistant steel for USC steam turbines. J. Mater. Eng Perform. 20, 1613-1619 (2011)

J. Ejenstam, P. Szakálos, Long term corrosion resistance of alumina forming austenitic stainless steels in liquid lead. J. Nucl. Mater. 461, 164-170 (2015)

N.V. Grum-Grzhimailo, D.I. Prokof'ev, An X-ray diffraction study of hightemperature solid solutions in the Cr-Mo-W system. Zhurnal Neorganicheskoi Khimii 6, 1155-1164 (1961)

L.-F. He, P. Roman, B. Leng, K. Sridharan, M. Anderson, T.R. Allen, Corrosion behavior of an alumina forming austenitic steel exposed to supercritical carbon dioxide. Corros. Sci. 82, 67-76 (2014)

T. Horita, H. Kishimoto, K. Yamaji, Y. Xiong, N. Sakai, M.E. Brito, H. Yokokawa, Evaluation of laves-phase forming Fe-Cr alloy for SOFC interconnects in reducing atmosphere. J. Power Sources 176, 54-61 (2008)

Y. Hosoi, S. Moteki, Y. Shimoide, Y. Sasaki, K. Miyahara, Effect of nitrogen, carbon and tungsten on high-temperature oxidation of 12\% Cr-15\%Mn austenitic steel. ISIJ Int. 36, 834-839 (1996)

M. Igarashi, in Creep-resistant steels, ed. by F. Abe, T.-U. Kern, R. Viswanathan. Alloy design philosophy of creep-resistant steels (Woodhead Publishing Limited, Cambridge, 2008), pp. 539-572

M.-H. Jang, J. Moon, J.-Y. Kang, H.-Y. Ha, B.G. Choi, T.-H. Lee, C. Lee, Effect of tungsten addition on high-temperature properties and microstructure of alumina-forming austenitic heat-resistant steels. Mater. Sci. Eng. A 647, 163169 (2015)

J.-Y. Kang, H.-Y. Ha, M.-H. Jang, J. Moon, D.-W. Suh, T.-H. Lee, Underlying structure of bulky oxide nodule on alumina-forming austenitic stainless steel. Scr. Mater. 102, 63-66 (2015)

A.S. Khanna, Introduction to High Temperature Oxidation and Corrosion (ASM Int, Materials Park, $\mathrm{OH}, 2002$ )

X. Liu, T. Fujita, Effects of Mo and W contents on creep rupture strength and toughness of a $10 \% \mathrm{Cr}$ heat resistant steel. Tetsu-to-Hagané 74, 513-520 (1988)

Q. Lu, W. Xu, S. Van Der Zwaag, The computational design of W and co-containing creep-resistant steels with barely coarsening laves phase and $M_{23} C_{6}$ as the strengthening precipitates. Metall. Mater. Trans. A 45, 6068-6074 (2014)

K.-H. Mayer, F. Masuyama, in Creep-resistant steels, ed. by F. Abe, T.-U. Kern, R. Viswanathan. The development of creep-resistant steels (Woodhead Publishing Limited, Cambridge, 2008), pp. 15-77

K. Miyata, Y. Sawaragi, Effect of Mo and W on the phase stability of precipitates in low $\mathrm{Cr}$ heat resistant steels. ISIJ Int. 41, 281-289 (2001)

E.J. Opila, Volatility of common protective oxides in high-temperature water vapor: Current understanding and unanswered questions. Mater. Sci. Forum 461-464, 765-774 (2004)

J. Pavlů, M. Šob, AB initio study of C14 laves phases in Fe-based systems. J. Mining Metall. 48B, 395-401 (2012)

Periodic table from the Royal Society of Chemistry (n.d.), http://www.rsc.org/ periodic-table, (accessed 15 June 2016)

B.A. Pint, S. Dryepondt, M.P. Brady, Y. Yamamoto, Evaluation of commercial and next generation alumina-forming austenitic foil for advanced recuperators, Proc. ASME Turbo Expo 2013: Turbine Technical Conference and Exposition GT2013, June 3-7 (The American Society of Mechanical Engineers, San Antonio, 2013), pp. GT2013-G94940

A.R.-V. Put, K.A. Unocic, M.P. Brady, B.A. Pint, Performance of chromia- and alumina-forming $\mathrm{Fe}$ - and $\mathrm{Ni}$-base alloys exposed to metal dusting environments: The effect of water vapor and temperature. Corros. Sci. 92 58-68 (2015)

V. Ramakrishnan, J.A. McGurty, N. Jayaraman, Oxidation of high-aluminum astenitic stainless steels. Oxid. Met. 30, 185-200 (1988)

G. Rother, J.R. Keiser, M.P. Brady, KA. Unocic, L.M. Anobitz, K.C. Littrell, RA Peascoe-Meisner, M.L. Santella, D.J. Wesolowski, D.R. Cole, Small-angle 
neutron scattering study of the wet and dry high-temperature oxidation of alumina-forming stainless steels. Corros. Sci. 58, 121-132 (2012)

A. Taylor, N.J. Doyle, The constitution diagram of the tungsten-molybdenumosmium system. J. Less Common Met. 9, 190-205 (1965)

Thermo-Calc Software SSUB4 Substances database version 4 (n.d.), (Accessed 21 June 2016)

Thermo-Calc Software TCFE7 Steels/Fe-alloys database version 7 (n.d.), (accessed 12 July 2016)

Y. Tsuchida, K. Okamoto, Y. Tokunaga, Improvement of creep rupture strength of high Cr ferritic steel by addition of W. ISIJ Int. 35, 317-323 (1995)

Y. Yamamoto, M.P. Brady, Z.P. Lu, C.T. Liu, M. Takeyama, P.J. Maziasz, B.A. Pint, Alumina-forming austenitic stainless steels strengthened by laves phase and MC carbide precipitates. Metall. Mater. Trans. A 38A, 2737-2746 (2007b)

Y. Yamamoto, M.P. Brady, Z.P. Lu, P.J. Maziasz, C.T. Liu, B.A. Pint, K.L. More, H.M. Meyer, E.A. Payzant, Creep-resistant, $\mathrm{Al}_{2} \mathrm{O}_{3}$-forming austenitic stainless steels. Science 316, 433-436 (2007a)

Y. Yamamoto, M.P. Brady, M.L. Santella, H. Bei, P.J. Maziasz, B.A. Pint, Overview of strategies for high-temperature creep and oxidation resistance of aluminaforming austenitic stainless steels. Metall. Mater. Trans. A 42A, $922-931$ (2011)

Y. Yamamoto, G. Muralidharan, M.P. Brady, Development of $\mathrm{L1}_{2}$-ordered $\mathrm{Ni}_{3}(\mathrm{Al}, \mathrm{Ti})$ strengthened alumina-forming austenitic stainless alloys. Scr. Mater. 69, 816819 (2013)

Y. Yamamoto, M.L. Santella, M.P. Brady, H. Bei, P.J. Maziasz, Effect of alloying additions on phase equilibria and creep resistance of alumina-forming austenitic stainless steels. Metall. Mater. Trans. A 40A, 1868-1880 (2009a)

Y. Yamamoto, M.L. Santella, C.T. Liu, N.D. Evans, P.J. Maziasz, M.P. Brady, Evaluation of $\mathrm{Mn}$ substitution for $\mathrm{Ni}$ in alumina-forming austenitic stainless steels. Mater. Sci. Eng. A 524, 176-185 (2009b)

D.W. Yun, H.S. Seo, J.H. Jun, J.M. Lee, D.H. Kim, K.Y. Kim, Oxide modification by chi phase formed on oxide/metal interface of Fe-22Cr-0.5Mn ferritic stainless steel for SOFC interconnect. Int. J. Hydrog. Energy 36, 5595-5603 (2011)

D.W. Yun, H.S. Seo, J.H. Jun, J.M. Lee, K.Y. Kim, Molybdenum effect on oxidation resistance and electric conduction of ferritic stainless steel for SOFC interconnect. Int. J. Hydrog. Energy 37, 10328-10336 (2012)

\section{Publisher's Note}

Springer Nature remains neutral with regard to jurisdictional claims in published maps and institutional affiliations.

\section{Submit your manuscript to a SpringerOpen ${ }^{\circ}$ journal and benefit from:}

- Convenient online submission

- Rigorous peer review

- Open access: articles freely available online

High visibility within the field

- Retaining the copyright to your article

Submit your next manuscript at $\boldsymbol{\nabla}$ springeropen.com 